\title{
Improving the efficiency of planning training hours for cadets' weapon practice
}

\author{
Zinaida Kuznetsova ${ }^{1}$, Aleksey Chaban ${ }^{2 *}$, Larisa Kotkova $^{1}$, Ruslan Miftakhov ${ }^{1}$, Stanislav Kuznetsov ${ }^{1}$ \\ ${ }^{1}$ University of Management “TISBI”, 423806, Naberezhnye Chelny, Russia \\ ${ }^{2}$ Tyumen Higher Military Engineering Command school (Military Institute) named after Marshal of engineering troops A.I. \\ Proshlyakov», 625001, Tyumen, Russia
}

\begin{abstract}
Cadets' weapons practice is one of the important components of professional training. Its success is in the training hours' distribution and mastering the main tasks at the early stages of military training. The correct distribution of weapon practice means and methods is very important. Planning of all weapon practice means begins with the definition of conditions and logistics. It is important to implement the principles of sports training. The implementation of the sports training basic principles during the school year allows expanding the cadets ' body adaptation mechanisms to daily physical and mental stress. The development of innovative technologies for planning hours and the implementation of weapon practice tools allows to optimize and improve the effectiveness of cadets' military training from the first year. Methodological aspects of planning and calculating hours by types of cadets' weapon practice are presented, taking into account the tasks and direction of the training tools implementation. Difficulties are analyzed and ways to eliminate them in the process of improving the cadets weapon practice are found. The key tasks in the structure of weapon practice and the direction of their implementation are defined. The author's version of cadets' weapon practice planning allows to control and adjust both physical and mental loads.
\end{abstract}

\section{Introduction}

Cadets' weapon practice of military universities begins before entering educational institutions. The analysis of the future applicants rifle readiness in the period 2015-2018 showed that applicants knew about small arms and its technical characteristics.

The cadets' weapon practice should be important before the start of basic training. Its main hours should be implemented to improve the weapons' possession.

The program of students' personal qualities formation in educational activities as one of the real prerequisites for upgrading the training specialists in higher education (on the example of students of Volga State Academy of Physical Culture, Sports and Tourism, specialty "Service and Tourism") showed the effectiveness of planning educational hours to meet the needs of students [1].

The cadets' weapon practice is considered as a multi-year process. It includes the integration of all training types into the educational process. The necessity of weapon practice taking into account extreme conditions of implementation is noted. Implementation of the sports training principles in weapon practice allows integrating all types of training as a condition for increasing efficiency and creating a solid foundation for professionally applied physical training, improving professionally important qualities $[2,3,4,5,6,7,8,9,10]$.

The process of long-term cadets' weapon practice should be divided into several stages with the implementation of the main competitive method.

The first stage of training should be short and include the tasks of teaching basic skills and skills in small arms. The second stage is the formation of cadets ' needs for regular training in shooting and weapon practice.

The third stage of weapon practice can be implemented at all stages of higher education and is characterized by the improvement of physical and mental capabilities and the ability to realize oneself in extreme conditions.

The presented study considers the use of the main conditions for cadets' weapon practice planning according to the program, as well as in the conditions of training sessions.

\section{Materials and Methods}

\footnotetext{
* Corresponding author: chaban-zon-baron@mail.ru
} 
To implement the main goal of this work, we used the experimental base of the Tyumen Higher Military Engineering Command school (Military Institute) named after Marshal of engineering troops A.I. Proshlyakov, Russia, Tyumen. At the first stage, the cadets' attitude to weapon practice, their need for regular training in shooting was revealed. The analysis of the work program for weapon practice was carried out. During the cadets' survey at all stages of training, difficulties were identified. It was used in organizing the cadets' training process in weapon practice.

The difficulties encountered in the planning and organization of weapon practice are identified. The necessity of training cadets for additional actions during weapon practice is noted in order to avoid maladaptation of the body to mental stress. The results were recorded in the protocol for observations. A basic questionnaire was developed for both cadets and military specialists, as well as for trainers in the shooting sport.

The questionnaire includes basic questions to identify the key components of weapon practice and difficulties that need to be eliminated. The study involved cadets from all training groups and specialists working under the rifle training program.

\section{Results and discussion}

A questionnaire survey to identify the weapon practice effectiveness showed that there are shortcomings in the planning of training hours. Experts noted that the planning of training hours depends on the conditions of weapon practice. Due to the lack of shooting areas, more hours are devoted to theoretical training and organization of cadets (39\%). It is noted that the state of small arms is also important. Sometimes $15 \%$ of the training time is spent on small arms training.

Figure 1 clearly shows the main conditions that must be taken into account when planning cadets' weapon practice.

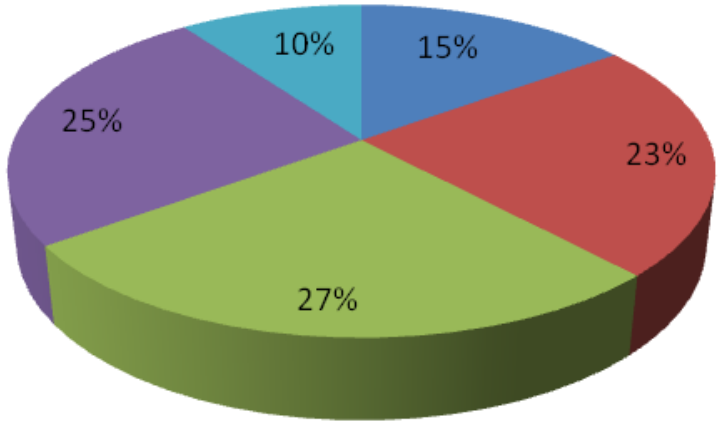

Weapon practice spaces

- State of small arms

Poor physical fitness

- Low level of weapon proficiency

Hours

Fig. 1. Results of cadets' questionnaire survey on identifying the causes that affect the effectiveness of weapon practice.

The figure shows that the weapon practice space does not satisfy $15 \%$ of the respondents. It is determined by the insufficient level of design. The state of small arms does not satisfy $23 \%$ of respondents. Difficulties are noted in the accuracy of aiming small arms at the target, in reducing the sense of squeezing the descent and showing more fluctuations in the weapon. It is important to note that $39 \%$ of respondents noted the presence of rough aiming of small arms.

According to $27 \%$ of respondents, it is impossible to exclude poor physical training of cadets, manifested in the inability to maintain a static posture, as well as in holding their breath. $25 \%$ of respondents rates their weapon practice as a low level of small arms mastery.

$10 \%$ of respondents identify a lack of studying hours planning. They note that the training hours are not planned enough.

Analysis of the specialists' survey results showed the presence of various difficulties in weapon practice. The main difficulties are: lack of psychological training, low level of self-control among cadets. Cadets want to get a good result quickly and without any effort. They are ambitious, self-confident, and therefore neglect other types of training. Experts associate this situation with the indifferent attitude of cadets to their physical condition.

There are presented options for the distribution of training hours in one training session on weapon practice.

Table 1 shows the distribution of training hours depending on the tasks of cadets' weapon practice. The number of classes and the amount of time allocated for each lesson should be approximately planned in advance and experimentally justified. In our example, we present a pedagogical model of the time distribution and number of classes depending on the tasks of weapon practice. About $22 \%$ should be allocated for improving weapon practice.

Table 1. Training hours' distribution depending on the weapon practice tasks.

\begin{tabular}{c|c|c|c|} 
Number of & Main tasks of the lesson & Session duration & Organizational and methodological \\
\hline
\end{tabular}




\begin{tabular}{|c|c|c|c|}
\hline classes & & & guidelines (techniques) \\
\hline $2-3$ & $\begin{array}{l}\text { Organization of the group for training classes. } \\
\text { Preparation of classes space. Checking the alert. } \\
\text { Checking basic knowledge. } \\
\text { Focus on the upcoming work with weapons. } \\
\text { Making weapons. }\end{array}$ & $3-5 \min$ & $\begin{array}{l}\text { Motivate them to do something. To } \\
\text { check the state of health and mood. } \\
\text { Mentally prepare yourself for future } \\
\text { work. To present the programme of } \\
\text { activities. Conduct a warm-up session. }\end{array}$ \\
\hline $4-5$ & $\begin{array}{l}\text { Achieve balance when performing the preparation. } \\
\text { Learn to freeze in position and maintain external } \\
\text { immobility in the position of preparation and } \\
\text { aiming. }\end{array}$ & $10-15 \mathrm{~min}$ & $\begin{array}{l}\text { Pay attention to the immobility of the } \\
\text { body. control the work of the muscles. } \\
\text { Keep the weapon stationary. }\end{array}$ \\
\hline $2-3$ & Take aim and squeeze the trigger. & $10-15 \mathrm{~min}$ & Control the movement of the forefinger. \\
\hline $4-5$ & $\begin{array}{l}\text { Make a shooting dominant. Exclude strong } \\
\text { fluctuations of the weapon. Overcome poor } \\
\text { stability when aiming }\end{array}$ & $10-15 \min$ & $\begin{array}{l}\text { Control your thoughts. Keep in mind } \\
\text { only one set of "Hit the target". } \\
\text { Completely go to work. }\end{array}$ \\
\hline $5-10$ & $\begin{array}{l}\text { To control all actions. Learn to identify the causes } \\
\text { of mistakes. }\end{array}$ & $5-10 \mathrm{~min}$ & Control the consistency of motor actions. \\
\hline $4-6$ & $\begin{array}{l}\text { Fight the feeling of insecurity. To monitor the } \\
\text { fatigue of the body. Watch for attention. }\end{array}$ & & $\begin{array}{l}\text { Monitor your pulse and breathing rate. } \\
\text { Control the effort. }\end{array}$ \\
\hline $15-20$ & Training and control shooting & $20 \mathrm{~min}$ & Implement the competitive method in \\
\hline $100 \%$ & Improvement of weapon practice & $10 \mathrm{~min}$ & \\
\hline
\end{tabular}

The implementation of the competitive method and principles of sports training allows you to increase the effectiveness of each class by $15 \%$.

Cadets' weapon practice is based on the content of weapon practice. There is a need to control the independent work of cadets with a clear indication of homework. For example, when passing the control standards, a cadet made a mistake such as a discrepancy between the preparation and aiming. His further work will be to correct this mistake. This approach makes it easier to master the motor action and bring it to automatism.

When drawing up a plan for independent work, the cadet and the teacher develop measures for periods, taking into account the decrease and increase in physical activity. Control over the physical and mental state of cadets allows to adjust physical activity and choose the means and methods for this particular situation.

The amount of time for independent training and sports training is adjusted by specialists to avoid increasing the psychological load. The final result of shooting depends on the quality distribution of hours for weapon practice. The excessive loads associated with the preparation and shooting sometimes lead to slowness of the shooting itself.

\section{Conclusions}

Thus, the work carried out on planning training hours taking into account the tasks of cadets' weapon practice allows to create a pedagogical model of implementation, taking into account the number of classes required to solve each specific task. The effectiveness of planning cadets ' training hours depends on each stage of training:

- from the conditions of sports facilities;

- from the state of small arms;

- from the acquisition of shooting training skills and abilities;

- from the initial level of physical fitness;

- on the level of small arms proficiency and fire readiness;

- from integrating the principles of sports training into the educational process of cadets;

- from the correct distribution of training hours and hours for independent work on weapon practice.

\section{References}

1. Z.M. Kuznetsova, N.A. Chernova, Pedagogico-psychological and medico-biological problems of physical culture and sports, 1(18), 143-149 (2011). URL: http://www.journal-science.org/ru/article/378.html

2. Z. Kuznetsova, A. Kuznetsov, I. Mutaeva, G. Khalikov, A. Zakharova, In Proceedings of the 3rd International Congress on Sport Sciences Research and Technology support (SCITEPRESS, 156-160, 2015)

3. A.P. Slozhenikin, Modern problems of the Humanities and natural Sciences: proceedings of the XXVI Intern. scientificpractical conference (M., 187-194, 2015)

4. I.U. Syuzev, Training of personnel for law enforcement agencies: modern trends and educational technologies: materials XX all-Russian scientific-methodological conference (Irkutsk, 163-167, 2015)

5. A.N. Taran, A.A. Boikov, Society and law, 1(47), 325-329 (2014)

6. N.N. Ustyuzhanin, Topical issues of training police officers to the lawful use of firearms: science, practice, pedagogy, psychology (M., 126-136, 2015)

7. I.V. Frolova, Candidate's thesis (Khabarovsk, 2004)

8. A.S. Kuznetsov, Z.M. Kuznetsova, Russian Journal of Physical Education and Sport, 14(4), 5-7 (2019). DOI: 10.14526/20704798-2019-14-4-5-7 
9. E.M. Khvastunova, Bulletin of the Barnaul law Institute of the Ministry of internal Affairs of Russia, 1(285), 65-66 (2015)

10. E.N. Chokotov, U.V. Grigorchak, International Journal of Applied and Fundamental Research, 12-8, 1540-1546 (2016) 